\title{
ANALISA NILAI KEKASARAN PERMUKAAN MAGNESIUM YANG DIFREIS DALAM KONDISI TERSUPLAI UDARA DINGIN
}

\author{
Gus ri Akhyar Ibrahim \\ Jurusan Teknik Mesin, Universitas Lampung, Jl. Prof. Soemantri Brodjonegoro, No.1, \\ Bandar Lampung 35145, \\ Gusri.akhyar@eng.unila.ac.id
}

\begin{abstract}
ABSTRAK
The use of magnesium material, as alternative to iron and steel, is becoming more popular. Besides the fact that it is lighter, magnesium is popular because it is available in a quite large quantity in this world. To make magnesium to be a machine component, there is a process needed to be done, which is known as machining process. The machining process done in several conditions doe to the pharamater or factor in machining process. . The examples of cutting pharameter are feed rate, cutting speed, and deep of cutting. This research used magnesium as the material of research. The purpose of this research is to investigate the influence of cutting pharameter to the surface roughness of magnesium machined with milling process ang supplied with cooling air from vortex tube cooler. Cutting pharameter used in this research are feed rate and cutting speed. Feed rate used was three levels, those are $0,15 \mathrm{~mm} / \mathrm{rev}, 0,20 \mathrm{~mm} / \mathrm{rev}$, and $0,25 \mathrm{~mm} / \mathrm{rev}$. Cutting speed used also three levels, those are 23,18 m/min, 32,15 m/min and 42,7 m/min. Cooling air is released from vortex tube cooler with $15^{\circ} \mathrm{C}$ of temperature. The result of this research is found that feed rate affect the number of magnesium surface roughness very significan. It can makes the number of surface roughness higher. Another pharameter, cutting speed also affect the number of magnesium surface roughness. It can make the number of surface roughness decreased. The number of magnesium surface roughness is also affected by nose radius, vibration, and cutting force.
\end{abstract}

Keywords: magnesium material, surface roughness, milling, cutting pharameter, cooling air.

\section{PENDAHULUAN}

Magnesium adalah salah satu jenis logam yang dikategorikan logam ringan, di antara beberapa logam ringan yang biasa digunakan dalam struktur. Unsur magnesium ditemukan pada tahun 1808 di Inggris oleh Sir Humphrey Davey, pertama kali diproduksi oleh Deville dan Caron di Perancis pada tahun 1863. Magnesium termasuk unsur yang berlimpah yang ada dibumi, sekitar $2 \%$ terdapat pada kulit bumi dan terlarut di dalam air laut dengan konsentrasi rata-rata $0,13 \%$. Magnesium ditemukan dalam 60 jenis mineral, di antaranya hanya dolomit, magnesit, dan carnalit, yang biasa dijadikan produk komersial [1].

Magnesium memiliki sifat ringan, mudah terbakar dan mudah bereaksi dengan logam lain. Oleh karena itu, magnesium tidak cukup kuat dalam bentuk yang murni, sehingga magnesium dipadukan dengan berbagai elemen untuk mendapatkan sifat yang lebih baik, terutama kekuatan untuk rasio berat yang tinggi. Banyak diantara paduan magnesium sesuai untuk proses pengecoran, pembentukan, dan pemesinan untuk mendapatkan kualitas komponen yang baik. Salah satu sifat magnesium yang dominan adalah mudah beroksidasi 
dengan cepat (pyrophpric), sehingga ada resiko/bahaya kebakaran yang mungkin terjadi. Oleh karena itu perlu ada tindakan pencegahan yang harus diambil ketika proses permesinan, grinding, atau pengecoran pasir magnesium. Meskipun demikian produk yang terbuat dari magnesium dan paduannnya tidak menimbulkan bahaya kebakaran selama proses pembuatannnya dapat dikontrol [2]..

Ada beberapa penelitian yang kebanyakan dilakukan untuk mengetahui sifat-sifat mekanik dan metalurgi magnesium. Penelitian mengenai pemesinan magnesium meski sedikit seperti yang dilakukan oleh Fang [3] bertujuan untuk mengetahui pengaruh dari temperatur sisi ( flank temperature) selama proses pemotongan paduan magnesium dengan menggunakan kecepatan tinggi (high speed) terhadap kemungkinan terjadinya kebakaran pada paduan magnesium. Hal itu dapat diketahui dengan melakukan pemotongan terhadap paduan magnesium dengan berbagai kondisi temperatur dan melihat hasil uji SEM pada serpihan hasil pemotongan paduan magnesium. Hasilnya dapat diketahui bahwa dibawah suhu $302 \mathrm{C}$ tidak ditemukan adanya titik nyala api pada serpihan. Penelitian lain adalah yang dilakukan oleh Buldum [4] yang bertujuan untuk mengetahui bagaimana sifat kemampumesinan (machinability) dari magnesium dalam proses pemesinan, yaitu pembubutan, freis dan pengeboran. Dalam penelitiannya Buldum,dkk merekomendasikan penggunaan kecepatan potong yang lebih rendah jika dibandingkan dengan kecepatan potong yang digunakan pada pemotongan magnesium. Peningkatan kecepatan potong akan mengakibatkan temperatur permukaan benda kerja meningkat dan geram yang dihasilkan ketebalannya akan lebih rendah. Semakin rendah kecepatan potong maka geram akan semakin besar dan temperatur permukaan benda kerja juga akan rendah. Pada penelitian ini akan dibahas mengenai kekasaran permukaan magnesium setelah dilakukan proses pemesinan (milling) dengan menggunakan pendingin udara (air cooling). Penelitian ini akan membahas kekasaran permukaan magnesium yang diberi udara dingin selama proses milling.

\section{METODOLOGI PENELITIAN}

Vortex tuve merupakan alat untuk mendapatkan udara bertekanan dengan suhu rendah, yang digunakan untuk mendinginkan benda kerja yang sedang dimesin. Instalasi vortex tube dipasang di mesin bubut yang dilengkapi dengan kompresor, pressure gauge valve dan vortex chamber. Pemasangan selang harus dipastikan terpasang dengan tepat, kekencangan baut selang pada kompresor dan menempatakan vortex tube pada posisi yang tepat pada mesin freis. Adapun suhu pendingin keluaran vortex tube adalah $15^{\circ} \mathrm{C}$.

Proses pengefreisan dilakukan menggunakan mesin freis konvensionan dengan tiga macam kecepatan potong dan gerak makan.. Kecepatan potong yang digunakan adalah 23,86 $\mathrm{m} / \mathrm{min}, 32,15 \mathrm{~m} / \mathrm{min}$ dan $42,7 \mathrm{~m} / \mathrm{min}$. Adapun gerak makan yang digunakan adalah 0,15 $\mathrm{mm} / \mathrm{rev}, 0,20 \mathrm{~mm} / \mathrm{rev}$ dan $0,25 \mathrm{~mm} / \mathrm{rev}$. Parameter tersebut digunakan untuk memproses pengefreisan benda kerja menggunakan udara kering dan pendingin (dry machining) sebagai pendingin mata pahat. Pada tahapan ini dilakukan pengukuran kekasaran terhadap permukaan magnesium yang telah di mesin, yaitu berupa pengukuran kekasaran permukaan menggunakan alat surface tester. Pada tiap-tiap pengukuran kekasaran permukaan dilakukan 
sebanyak 3 kali. Hal ini guna memperoleh hasil pengukuran yang lebih akurat dan meminimalisir eror.

\section{HASIL DAN PEMBAHASAN}

\section{Pengaruh gerak makan te rhadap kekasaran pe rmukaan magnesium.}

Gambar 1 menunjukkan bahwa nilai kekasaran permukaan magnesium mengalami peningkatan jika gerak makannya juga ditingkatkan. Hal ini berarti pada kecepatan potong yang sama, menaikkan gerak makan akan memperbesar nilai kekasaran (Ra) [5]. Gerak makan memang berpengaruh sangat signifikan terhadap nilai kekasaran permukaan. Hal ini dapat kita lihat pada gerak makan $0,25 \mathrm{~mm} / \mathrm{rev}$. Pada grafik dapat diamati bahwa telah terjadi kenaikan kekasaran permukaan yang cukup signikan saat pemesinan menggunakan gerak makan 0,25 mm/rev. Nilai kekasaran permukaan mengalami kenaikan yang sangat signifikan jika dibandingkan dengan pemesinan menggunakan gerak makan $0,20 \mathrm{~mm} / \mathrm{rev}$. Hal ini berarti pada saat pemesinan menggunakan gerak makan $0,25 \mathrm{~mm} / \mathrm{rev}$, maka pengaruh gerak makan amat signifikan terhadap peningkatan kekasaran permukaan magnesium, sedangkan peran kecepatan potong seolah tidak ada. Ini pernah diungkapkan oleh seorang peneliti, yaitu Zubaidi [6] yang mengungkapkan bahwa penambahan rpm untuk kecepatan potong akan menurunkan kekasaran tidak lebih dari $10 \%$ tiap $100 \mathrm{rpm}$. Menurut penelitian Asmed [7] Gerak pemakanan berpengaruh sangat signifikan terhadap kekasaran permukaan disebabkan gerak pemakanan adalah jarak yang ditempuh pahat perputaran.

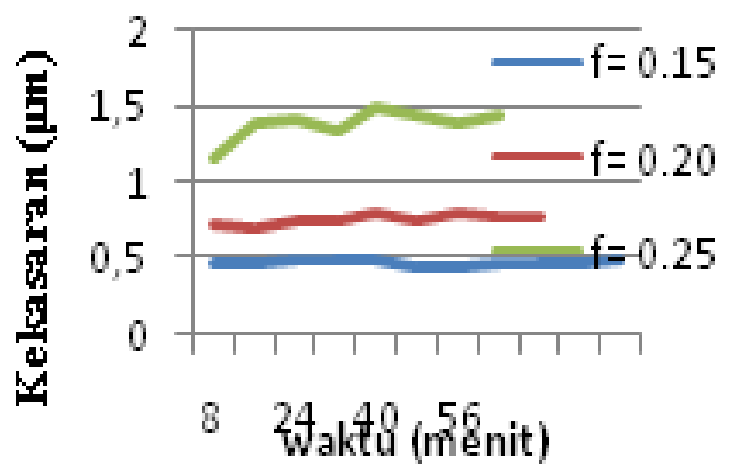

Gambar 1. Grafik kekasaran terhadap waktu dengan kecepatan 23,86 m/min

Pada Gambar 2 dapat diamati pengaruh gerak makan pada kecepatan potong 32,15 $\mathrm{m} / \mathrm{min}$. Tidak jauh berbeda dengan sebelumnya, pemesinan pada kecepatan $32,15 \mathrm{~m} / \mathrm{min}$ juga akan mengalami peningkatan kekasaran permukaan magnesium jika gerak makan juga ditingkatkan. Namun, kenaikan signifikan terjadi pada gerak makan 0,20 mm/rev. Hal ini berarti bahwa menaikkan kecepatan potong menjadi $32,15 \mathrm{~m} / \mathrm{min}$ akan menjadikan permukaan magnesium menjadi lebih halus. Jika kita lihat pada tiap gerak makan yang digunakan maka akan terjadi penurunan kekasaran permukaan jika dibandingkan dengan pemesinan menggunakan kecepatan potong 23,86 m/min. Pengaruh kecepatan potong 32,15 $\mathrm{m} / \mathrm{min}$ tidak begitu signifikan pengaruhnya untuk gerak pemakanan $0,20 \mathrm{~mm} / \mathrm{rev}$, dapat kita 
katakan bahwa saat pemesinan menggunakan gerak makan $0,20 \mathrm{~mm} / \mathrm{rev}$ akan terjadi peningkatan kekasaran yang sangat signifikan, tetapi tidak terlalu signifikan kenaikan kekasarannya saat pemesinan pada gerak pemakanan $0,25 \mathrm{~mm} / \mathrm{rev}$.

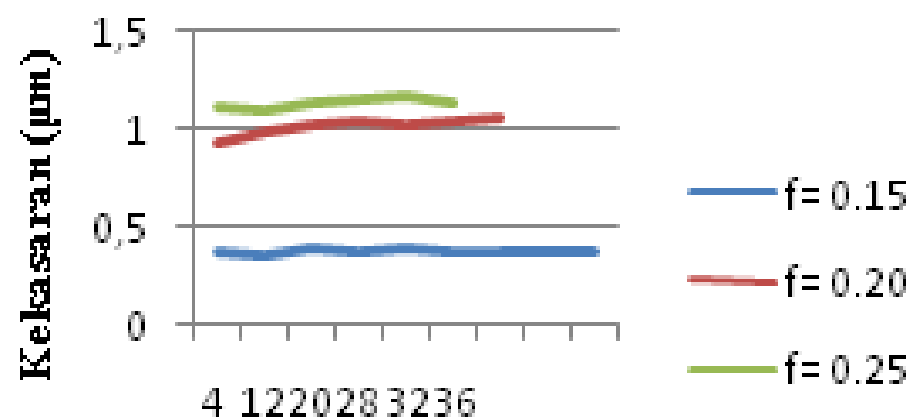

Waktu (menit)

Gambar 2. Grafik kekasaran terhadap waktu dengan kecepatan 32,15 m/min

Gambar 3 menggambarkan bagaimana pengaruh gerak makan pada kecepatan potong $42,7 \mathrm{~m} / \mathrm{min}$. Dapat kita lihat bahwa pengaruh gerak makan pada kecepatan potong 42,7 $\mathrm{m} / \mathrm{min}$ berbanding terbalik dari kecepatan potong $23,86 \mathrm{~m} / \mathrm{min}$ dan $32,15 \mathrm{~m} / \mathrm{min}$. Kekasaran permukaan magnesium justru mengalami penurunan seiring dengan meningkatnya gerak makan pemesinan magnesium. Dapat kita lihat bahwa paga gerak makan $0,15 \mathrm{~mm} / \mathrm{rev}$, nilai kekasaran magnesium mengalami kenaikan jika dibandingkan dengan pemesinan menggunakan kecepatan $32,15 \mathrm{~mm} / \mathrm{rev}$. Hal ini memang dimungkinkan dikarenakan nilai kekasaran tidak hanya dipengaruhi oleh faktor gerak makan dan kecepatan potong. Nilai kekasaran juga dipengaruhi oleh faktor nose radius pahat. Jika pahat telah mengalami kerusakan sehingga nose radiusnya menjadi lebih besar, maka memperbesar gerak makan justru akan menurunkan nilai kekasaran.

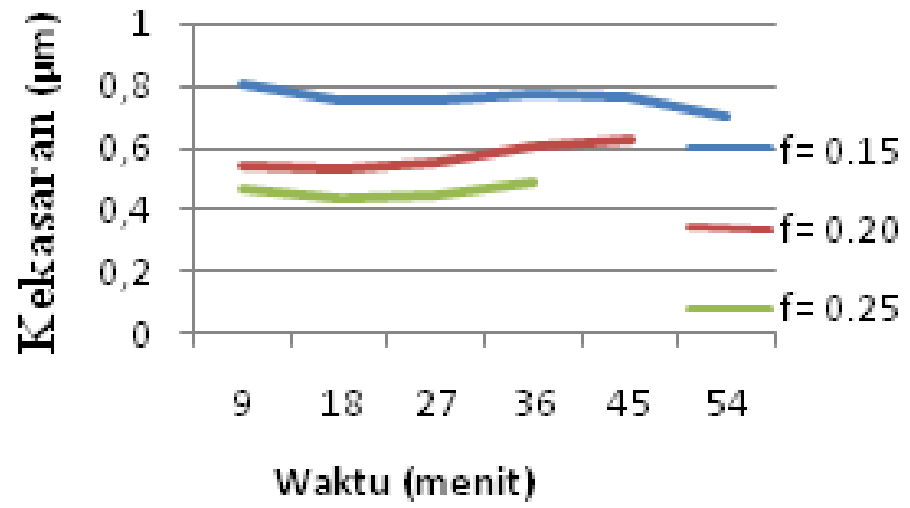

Gambar 3 Grafik kekasaran terhadap waktu dengan kecepatan 42,7 m/min 


\section{Pengaruh kecepatan potong terhadap nilai kekasaran permukaan magnesium}

Pada Grafik 4 dapat diamati bahwa tingkat kekasaran magnesium akan mengalami penurunan kecuali pada kecepatan potong $42,7 \mathrm{~m} / \mathrm{min}$. Hal ini berarti pada pemesinan dengan gerak makan $0,15 \mathrm{~mm} / \mathrm{rev}$, kekasaran permukaan magnesium akan turun, kecuali pada kecepatan potong 42,7 m/min yang mengalami kenaikan. Menurut penelitian Jonoadji [8] selaian gerak makan dan kecepatan potong, nilai Ra (kekasaran) juga dipengaruhi oleh nose radius pahat. Dari rumus tersebut dapat kita lihat bahwa faktor $\mathrm{nr}$ (nose radius) pahat juga mempengaruhi nilai Ra. Pada kecepatan potong yang tinggi, dimungkinkan nose radius pahat mengalami kerusakan sehingga ukurannya menjadi lebih kecil. Hal ini menyebabkan nilai Ra menjadi lebih besar dari yang seharusnya.

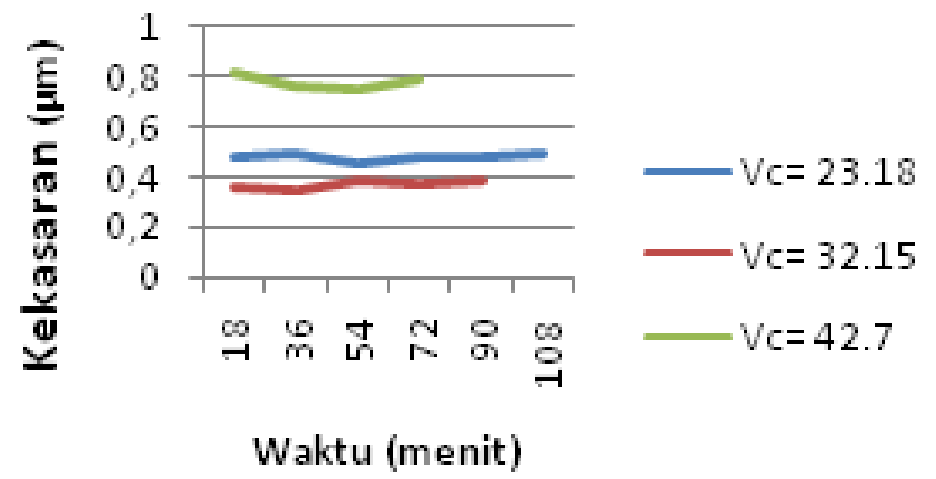

Gambar 4. Grafik kekasaran terhadap waktu dengan gerak makan 0,15 mm/rev

Gambar 5 menunjukkan bahwa kekasaran permukaan magnesium akan mengalami kenaikan pada kecepatan potong 32,15 m/min. Namun pada kecepatan potong 42,7, kekasaran permukaan magnesium mengalami penurunan. Ini artinya jika pemesinan dilakukan dengan gerak makan $0,20 \mathrm{~mm} / \mathrm{rev}$ dan menggunakan kecepatan potong yang tinggi, yaitu $42,7 \mathrm{~m} / \mathrm{min}$ maka kekasaran permukaan magnesium mengalami penurunan atau lebih halus. Pada kecepatan potong 32,15 m/min, nilai kekasaran justru mengalami kenaikan. Hal ini sama dengan kasus yang terjadi sebelumnya, yaitu adanya faktor nose radius yang mengalami kerusakan sehingga nilai kekasaran permukaan menjadi lebih besar. Perubahan nose radius akan memengaruhi bentuk geometri ujung pahat. Hal ini akan sangat signifikan pengaruhnya terhadap nilai kekasaran pahat [9]. Meskipun secara teori umum nilai kekasaran permukaan akan turun pada kecepatan potong 32,15 m/min, akan tetapi karena adanya faktor nose radius mengakibatkan nilai kekasaran permukaan magnesium dimungkinkan untuk mengalami kenaikan. Selain faktor nose radius pahat, memang dimungkinkan ada faktorfaktor lain yang menjadi penyebabnya, misalnya panas yang timbul, ketidak-presisian pahat, serta getaran yang timbul selama proses pemesinan [10]. 


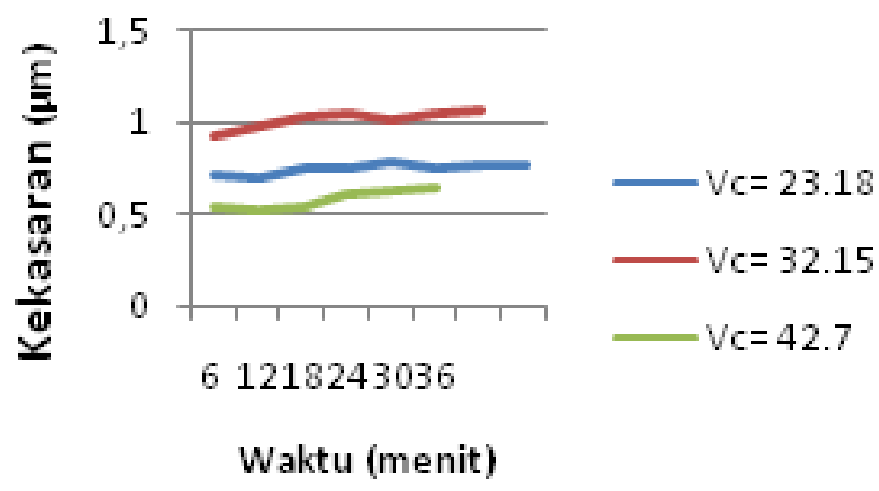

Gambar 5. Grafik kekasaran terhadap waktu dengan gerak makan 0,20 mm/rev

Gambar 6 menunjukkan bahwa tingkat kekasaran permukaan magnesium terus mengalami penurunan. Berdasarkan fenomena ini, dapat kita katakan bahwa pemesinan dengan menggunakan gerak makan yang tinggi akan mengakibatkan kekasaran permukaan magnesiun menurun seiring dengan naiknya kecepatan potong yang digunakan pada proses pemesinan. Beberapa peneliti juga menemukan fenomena yang sama seperti hal diatas. Asmed dan Yusri [11] juga menemukan bahwa pada gerak makan yang sama dengan menaikkan kecepatan potong akan menurunkan nilai kekasaran permukaan. Mereka mengungkapkan bahwa nilai kekasaran amat bergantung pada gerak makan, geometri pahat dan kecepatan potong. Pada gerak makan yang sama, menaikkan kecepatan potong akan menurunkan nilai kekasaran permukaan benda kerja.

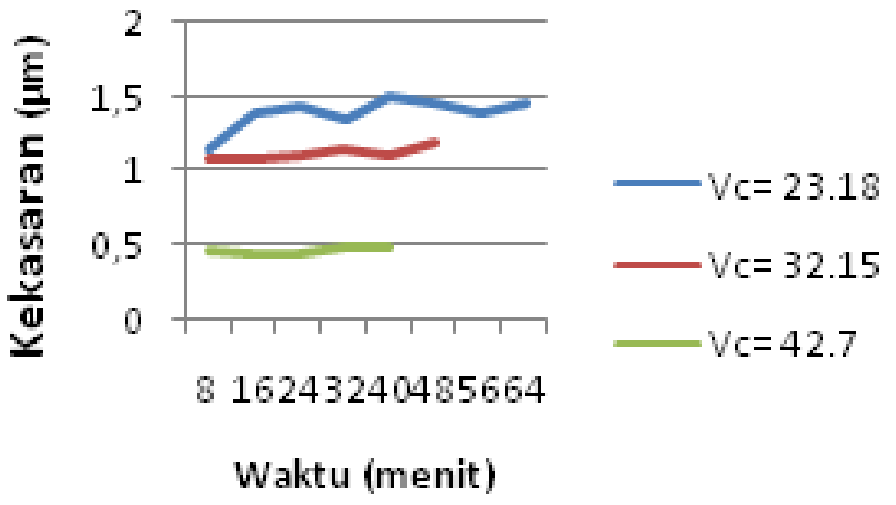

Gambar 6. Grafik kekasaran terhadap waktu dengan gerak makan 0,25 mm/rev

\section{KESIMPULAN}

Nilai kekasaran permukaan magnesium sangat dipengaruhi oleh parameter pemotongan, terutama gerak makan ( feed rate). Adapun kecepatan potong ( cutting speed) tidak berpengaruh signifikan terhadap peningkatan nilai kekasaran permukaan magnesium. Semakin tinggi gerak makan yang digunakan maka nilai kekasaran permukaan magnesium akan semakin besar. Nilai kekasaran permukaan magnesium juga dipengaruhi oleh faktorfaktor lain, antara lain nose radius, getaran yang timbul saat pemesinan, gaya pemotongan dan ketidak-presisian pahat. 


\section{DAFTAR PUSTAKA}

[1] G. Padmanaban, V. Balasubramaniana, G. Madhusudhan Redd. 2011. Fatigue crack growth behaviour of pulsed current gas tungsten arc, friction stir and laser beam welded AZ31B magnesium alloy joints. Centre for Materials Joining \& Research (CEMAJOR), Department of Manufacturing Engineering, Annamalai University, Annamalai Nagar 608002, India.

[2] Suhairi. 2010, Pengaruh Variabel Pemotongan Terhadap Kualitas Permukaan Produk dalam Meningkatkan Produktifitas, Jurnal, Jurusan Teknik Mesin Politeknik Negeri Padang.

[3] F.Z Fang, L.C. Lee, X.D. Liu. 2002. Journal of Mean flank temperature measurement in high speed dry cutting of magnesium alloy. Singapore Institute of Manufacturing Technology.

[4] Buldum, Berat Baris. Aydin SIK., Iskender Ozkul. 2011. Investigation of Magnesium Alloys Machinability. International Journal of Electronics, Mechanichal and Mechatronics Engineering Vol 3 Num 3 (361-368)

[5] Lukman. 2008. Automotive Applications of Magnesium andIts Alloys. Trans. Indian Inst.

[6] Zubaidi, A. 2012.Analisis Pengaruh Kecepatan Putar dan Kecepatan Pemakanan Terhadap Kekasaran Permukaan Material FCD 40 Pada Mesin Bubut CNC. Jurnal Unwahas. Semarang.

[7] Asmed, dan Yusri, M. 2002. Pengaruh parameter pemotongan terhadap kekasaran permukaan proses bubut untuk material ST37. Politeknik Negeri Padang.

[8] Jonoadji, N., Dewanto, J., 1999, Pengaruh Parameter Potong dan Geometri Pahat Terhadap Kekasaran Permukaan Pada Proses Bubut, Jurnal, Fakultas Teknik, Jurusan Teknik Mesin - Universitas Kristen Petra

[9] Kalpakjian, S. dan Schmid, S.R. 2001. Manufacturing Engineering and Technology international edition. USA : Prentice Hall

[10] Boothroyd, G dan Knight. 1989. Fundamental Machining and Machine Tools. Marcell: Dekker Inc.

[11]. Bhattacharyya, A. 1984. Metal Cutting Theory and Practice. India 